\title{
IMPLICAÇÕES BIOÉTICO-JURÍDICAS DO USO DA EDIÇÃO GENÉTICA COMO ALTERNATIVA TERAPÊUTICA NAS RELAÇÕES EM SAÚDE NO BRASIL
}

\author{
BIOETHICAL-LEGAL IMPLICATIONS OF THE USE OF GENETIC EDITING AS A \\ THERAPEUTIC ALTERNATIVE IN HEALTH RELATIONS IN BRAZIL
}

\author{
IMPLICACIONES BIOÉTICO-LEGALES DEL USO DE LA EDICIÓN GENÉTICA COMO
} ALTERNATIVA TERAPÉUTICA EN LAS RELACIONES DE SALUD EN BRASIL

\author{
Ana Thereza Meireles Araujo ${ }^{1}$ \\ Universidade Católica de Salvador (UCSal) \\ Rafael Silva Verdival dos Santos ${ }^{2}$ \\ Universidade Católica de Salvador (UCSal)
}

\begin{abstract}
RESUMO:
O presente estudo analisa as implicações bioéticas e jurídicas do uso da edição genética no âmbito das relações de saúde no Brasil. Para tanto, pretende pensar sua utilização à luz do sistema de saúde brasileiro, seja no âmbito público ou no âmbito da saúde suplementar. O advento do sistema CRISPR/Cas9 representa grande evolução no âmbito das terapias genéticas, já que é procedimento mais preciso, eficiente e acessível. O uso dessa tecnologia acelera a possibilidade de sua aplicação terapêutica, potencializando pesquisas direcionadas para o tratamento de graves patologias de viés genético. Tornou-se fundamental, na pesquisa, a demonstração da importância dos estudos genéticos e da medicina preditiva como meios de concretização da saúde na atualidade. Utilizou-se o método dedutivo com abordagem qualitativa, a partir de revisão bibliográfica de trabalhos científicos das áreas da Genética, da Bioética e do Direito, bem como documentos normativos relacionados à temática.
\end{abstract}

Palavras-chave:

Edição genética; terapia genética; relações em saúde; bioética; direito médico.

ABSTRACT: This study analyzes the bioethical and legal implications of using genetic editing in the context of health relations in Brazil. Therefore, it intends to think about its use in the light of the Brazilian health system, whether in the public sphere or in the scope of supplementary health. The advent of the CRISPR / Cas9 system represents a great evolution in the field of genetic therapies, since it is a more precise, efficient and accessible procedure. The use of this technology accelerates the possibility of its therapeutic application, enhancing research aimed at the treatment of serious pathologies of genetic bias. It has become essential, in research, to demonstrate the importance of genetic studies and predictive medicine as a means of achieving health today. The deductive method with a qualitative approach was used, based on a bibliographic review of scientific works in the areas of Genetics, Bioethics and Law, as well as normative documents related to the theme.

Keywords:

Gene editing; gene therapy; health relations; bioethics; medical law.

\footnotetext{
${ }^{1}$ Pós- Doutoranda em Medicina pelo Programa de Pós-Graduação de Medicina e Saúde da Faculdade de Medicina da Universidade Federal da Bahia (UFBA). Doutora em Relações Sociais e Novos Direitos pela Faculdade de Direito da Universidade Federal da Bahia (UFBA). Mestre em Direito Privado e Econômico pela Universidade Federal da Bahia (UFBA). Professora membro do Corpo permanente do Mestrado em Direito Fundamentais e Alteridade da Universidade Católica do Salvador (UCSal). Professora da Universidade do Estado da Bahia (UNEB), da Universidade Católica do Salvador (UCSal) e da Faculdade Baiana de Direito. Coordenadora da Pósgraduação em Direito Médico, da Saúde e Bioética da Faculdade Baiana de Direito. Líder do Grupo de Pesquisa JusBioMed - Direito, Bioética e Medicina. Orcid: https://orcid.org/0000-0001-9623-6103

2 Mestrando em Direito pela Universidade Católica do Salvador (UcSal). Pós-Graduado em Filosofia e Autoconhecimento: uso pessoal e profissional pela Pontifícia Universidade Católica do Rio Grande do Sul. Membro integrante do Grupo de Pesquisa JusBioMed - Direito, Bioética e Medicina. Orcid: https://orcid.org/0000-0001-8393-5618
} 
RESUMEN: La presente investigación analiza las implicaciones bioéticas y legales del uso de la edición genética en el contexto de las relaciones de salud en Brasil. Por lo tanto, se propone pensar su uso a la luz del sistema de salud brasileño, ya sea en la esfera pública o en el ámbito de la salud complementaria. La llegada del sistema CRISPR / Cas9 representa una gran evolución en el campo de las terapias genéticas, ya que es un procedimiento más preciso, eficiente y accesible. El uso de esta tecnología acelera la posibilidad de su aplicación terapéutica, potenciando la investigación dirigida al tratamiento de patologías graves de sesgo genético. Se ha vuelto esencial, en la investigación, demostrar la importancia de los estudios genéticos y la medicina predictiva como un medio para lograr la salud en la actualidad. Se utilizó el método deductivo con enfoque cualitativo, basado en una revisión bibliográfica de trabajos científicos en las áreas de Genética, Bioética y Derecho, así como documentos normativos relacionados con el tema.

Palabras clave:

Edición genética; terapia de genes; relaciones de salud; bioética; ley médica.

\section{INTRODUÇÃO}

Os avanços científicos no âmbito da edição genética, potencializados pelo surgimento da tecnologia CRISPR/Cas9, trazem consigo a necessidade de um novo olhar sobre as questões de saúde, em virtude do seu grande potencial terapêutico. Frisa-se, como realidade contemporânea, a importância do viés preditivo da medicina, que pode atuar como instrumento preventivo ou profilático diante da possibilidade de instauração de determinada patologia. Assim sendo, o desenvolvimento e incorporação dessa nova terapia torna-se, na atualidade, instrumento relevante para a efetivação do direito à saúde.

O presente artigo tem como ponto fundamental a investigação das implicações bioéticojurídicas decorrentes do uso da edição genética no contexto das relações de saúde no Brasil. O objetivo deste trabalho é analisar como a edição genética pode ser pensada no âmbito do sistema de saúde brasileiro, considerando as dificuldades de sua absorção como um instrumento terapêutico e as implicações que a sua prática pode ensejar.

A fim de realizar essa reflexão, valendo-se das contribuições bioéticas e jurídicas do professor Carlos Romeo Casabona, aborda-se o desenvolvimento da Genética, através de suas múltiplas possibilidades e consequências, e o advento da edição genética e do sistema CRISPR/Cas9, considerando o potencial terapêutico avançado dessa nova tecnologia. Em seguida, investiga-se a edição genética como uma realidade que possa ser possivelmente considerada pelo sistema de saúde brasileiro, seja público ou privado. O intuito é apontar como a edição genética pode auxiliar na efetivação do direito à saúde no país, apresentando suas vantagens técnicas e seus aspectos econômicos, bem como suas dificuldades de aplicação. Como contributo essencial, este estudo aponta para a elaboração de uma legislação fundamentada em critérios bioéticos, a partir das bases da doutrina de Casabona, em 
documentos internacionais e na experiência de outros países, que coíba danos e impossibilite práticas neoeugênicas, garantindo a integridade e a segurança dos sujeitos envolvidos.

O estudo consiste em revisão bibliográfica de trabalhos das áreas médica, bioética e jurídica e pesquisa em documentos normativos, estando pautado na perspectiva metodológica dedutiva com abordagem qualitativa.

\section{O ACESSO AO GENOMA HUMANO: DAS CONTRIBUIÇÕES DE CARLOS CASABONA À EDIÇÃO GENÉTICA}

Analisar a edição genética como possibilidade terapêutica demanda compreender o seu contexto de surgimento, a partir do esclarecimento de questões relacionadas ao avanço da área da Genética. Assim, para uma análise dos fundamentos bioéticos e jurídicos relacionados ao tema, é necessário compreender previamente a sua dimensão médica e os seus aspectos técnicos.

O surgimento desse novo paradigma é consequência de um processo de construção científica que ocorre há décadas. Os avanços nas pesquisas envolvendo o genoma humano trazem novos conceitos e problemas que configuram grande desafio para a Bioética e para o Direito. Nesse cenário de complexidades conceitual e técnica, o pensamento do professor Carlos Romeo Casabona constitui base doutrinária fundamental para construção de uma disciplina ético-normativa que conduza a prática da edição genética.

Carlos Maria Romeo Casabona, Catedrático da Universidad del País Vasco e Diretor da Cátedra de Derecho y Genoma Humano, é Doutor em Direito e em Medicina e transita epistemologicamente entre essas duas áreas de conhecimento (JIMÉNEZ, 2016, p.2). Os escritos do autor são marcos científicos mundialmente conhecidos e consolidam a necessidade de consubstanciar a evolução das descobertas da Genética a partir dos limites advindos da Bioética e do Direito. Os conhecimentos jurídicos e médicos de Casabona congregam intersecções entre Direito e Medicina, pressuposto fundamental quando se pretende pensar sobre os complexos problemas que nascem dessa zona comum. Ciente dessa complexidade, ele enfrenta e analisa as implicações jurídicas dos avanços da biologia molecular e da genética através de uma perspectiva indispensavelmente multidisciplinar (JIMÉNEZ, 2016, p. 3).

Disso resulta que, neste artigo, a contextualização do estudo da edição genética tem como elemento antecedente o apontamento contingenciado de algumas reflexões científicas de Carlos Casabona. O leque de desdobramentos bioéticos decorrentes da prática de manipulações biológicas é extenso, o que traz complexidade ao enfrentamento das problemáticas emergentes. 
Casabona diferencia esses problemas, deixando claro que, embora oriundos de um elemento em comum (a manipulação biológica), têm naturezas, finalidades e consequências distintas. Por conta disso, é possível encontrar nas obras do professor reflexões sobre os problemas decorrentes da clonagem, da engenharia genética, da eugenia, do acesso à informação genética, da biossegurança e de outros desdobramentos relacionados à área.

Desde a execução do Projeto Genoma, na década de 1990, Casabona destacava a importância da multidisciplinaridade como elemento de aproximação das questões jurídicas que permeiam a genética. Assim, frisava ele a necessidade de proximidade entre as Ciências Biomédicas, a Ética e o Direito através da Bioética (CASABONA, 1995, p.15-16).

Desde 1995, Casabona trouxe reflexões sobre aspectos da genética que ainda hoje são frequentemente discutidos. São os casos, por exemplo, da análise genética e da possibilidade de intervenções no genoma através do DNA recombinante. No que tange aos limites sobre o acesso às informações genéticas do sujeito, questionou se os indivíduos seriam obrigados à submissão compulsória de exames genéticos a fim de determinar paternidade biológica ou auxiliar em uma investigação criminal, trazendo à tona o conflito entre a liberdade, intimidade e autonomia diante dos interesses gerais de uma comunidade (CASABONA, 1995, p. 18-19). A discussão sobre os limites do uso da informação genética perpassa, de maneira significativa, às construções de Casabona, que considera fundamental ponderar o acesso ao DNA diante de outros bens jurídicos envolvidos, como a autonomia, a identidade, a saúde e a intimidade.

A Ciência segue se desenvolvendo de maneira que "lo que parecía lejano o imposible se vislumbra ya en el horizonte, perfilándose sus contornos cada vez con mayor precisió” (CASABONA, 1995, p. 18). O descortinamento da compreensão dessa lógica da racionalidade científica é corroborado pelas distintas e sucessivas possibilidades da Genética com o passar dos anos, como o surgimento da clonagem, entre o final dos anos 1990 e início dos anos 2000.

Levando em consideração a possibilidade de clonagem de embriões humanos, parte-se da necessidade de identificar quais seriam os bens jurídicos a serem protegidos no contexto da clonagem e como essa técnica e seus resultados poderiam afetar tais bens (CASABONA, 2000, p.146). Ciente da complexidade dos conceitos que aborda, Casabona demonstra um cuidado metodológico pouco visto quando a temática transcende a abordagem puramente jurídica. Ao tratar de clonagem, faz questão de definir o que é a clonagem reprodutiva humana, destacando a importância dessa definição para a identificação de sua carga valorativa (CASABONA, 2000, p. 147; CASABONA, 2001, p.128).

Ao estabelecer os bens jurídicos envolvidos na clonagem, inicialmente, Casabona aponta a integridade física dos seres nascidos dessa técnica como um bem a ser protegido - 
embora reconheça que o estabelecimento de procedimentos totalmente seguros e confiáveis superaria a questão. Ainda nessas reflexões introdutórias, lembra da diversidade genética como elemento importante na preservação da espécie humana - em especial frente a doenças contagiosas ou agentes externos causadores de doenças. Porém, reconhece que "los riesgos de emprobecimiento del patrimonio genético humano serían muy remotos”. (CASABONA, 2000, p. 148). Casabona questiona a possibilidade do indivíduo clonado ser privado da condição de ser único, irrepetível e distinto de outros seres existentes - vivos ou mortos. (CASABONA, 2000, p. 148). Tais reflexões culminam nos estudos de hoje que deslegitimam a clonagem reprodutiva por reconhecerem o direito à identidade genética como integrante do arcabouço dos direitos da personalidade. Na sistemática brasileira dos direitos da personalidade, assumem-se que o rol enunciado pelo Código Civil não é taxativo e deve abarcar esferas da existência do indivíduo relacionadas à proteção também da individualidade do seu patrimônio genético.

Para contrapor o risco e a sedução do determinismo genético, entende Casabona que, cientificamente, na clonagem, não parece factível criar dois seres exatamente iguais - seja porque o DNA mitocondrial não é sempre o mesmo, em virtude da técnica utilizada; seja porque a personalidade de um indivíduo é também pautada por fatores familiares, culturais, sociais e temporais. (CASABONA, 2000, p. 149). É fundamental acentuar a importância de reflexões como essa que contribuem para a ressignificação dos limites da Genética e para redimensionamento do conhecimento social sobre sua real função.

A necessidade atual de redimensionar a função e o sentido da Genética parte do fato de que a mesma descortina, concomitantemente, promessas e dilemas. “A promessa é que em breve seremos capazes de tratar e prevenir uma série de doenças debilitantes. O dilema é que nosso recém-descoberto conhecimento genético também pode permitir a manipulação de nossa própria natureza [...]” (SANDEL, 2018, p.19), tendo como objetivo final a melhoria das características e das condicionantes humanas, escolhendo algumas e afastando outras. Esse dilema tem natureza aprioristicamente ética, mas, ao longo da evolução das necessidades sociais, passou a se relacionar diretamente com o Direito, consoante a sua função de construir limites às práticas que ofendam bens jurídicos que devem ser continuamente tutelados (MEIRELLES, 2014, p.22).

Como derivante das implicações da clonagem, surgem questões cada vez mais complexas que ensejariam limites à aplicação da técnica, como o ressurgimento do pensamento eugênico e o direito à origem biológica do sujeito clonado (CASABONA, 2000, p.151- 152). A possibilidade de clonar uma pessoa descortina possibilidades múltiplas relacionadas a direito 
fundamentais, fator que se comunica com a possibilidade de edição de genes, foco primordial dessa pesquisa.

Ainda no que tange à clonagem, Casabona apontou que a regulação normativa não se preocupa com os diferentes tipos de procedimentos existentes, fato que também aconteceu no Brasil com o advento da Lei 11.105/2005, em seu artigo 26. Para o autor, há uma "general pobreza argumentativa” no que diz respeito aos fundamentos dessas normas, que não indicam quais direitos humanos seriam afetados e nem o motivo de afetação (CASABONA, 2001, p.130).

A forma com que a legislações que versam sobre conteúdos tão especializados foi construída é objeto de críticas essenciais pelo autor, já que é visível a atecnia na construção do texto normativo e falta de compreensão, por vezes, das proposições postas. Essa é a realidade da lei brasileira de biossegurança, pouco compreendida pelos juristas e reveladora de uma série de incongruências, como a proibição da clonagem como gênero, sem ponderar as suas diferentes espécies - reprodutiva e terapêutica.

Os avanços na área da genética e da reprodução humana terminaram por também propiciar o ressurgimento das discussões sobre as práticas eugênicas, já que as condutas manipulatórias podem revelar decisões seletivas, calcadas em objetivos terapêuticos ou em fins de melhoramento sem motivações relacionadas à saúde.

Esse panorama divide as novas condutas eugênicas como a de natureza terapêutica, embasada em fundamentos médicos, e a de natureza de aperfeiçoamento, destituída de motivações científicas. Em matéria de procriação assistida, as decisões estão situadas num “âmbito de natureza privada e não acontecem de forma coercitiva”. (MEIRELLES, 2014, p.104). O âmbito das decisões que podem envolver escolhas seletivas revela, então, novas demandas de mercado, conduzidas por motivações individuais, padrões e anseios pessoais, fatores que constituem a chamada eugenia liberal (HABERMAS, 2004) ou a neoeugenia (CASABONA, 1999; CASABONA, 2012).

O valor preventivo das análises genéticas no cerne do processo de reprodução, hoje, acentuou as possibilidades neoeugênicas. Aconselhamentos genéticos, diagnósticos em gametas, embriões e fetos e a engenharia genética são técnicas relativamente novas, que promoveram o ressurgimento de possibilidades originadas nas ideias do pensamento eugênico, hoje, denominado de neoeugenia. Tal denominação tem por finalidade enfatizar as diferenças entre o pensamento eugênico atual e o pensamento eugênico do século XX (CASABONA, 1999, p.9-10). 
Os avanços científicos advindos do estudo da clonagem fomentaram descobertas no âmbito das células-tronco, mas teve como entrave o fato de que a Declaração das Nações Unidas sobre Clonagem Humana, de 2005, proibiu expressamente qualquer tipo de prática da conduta, o que inclui a espécie terapêutica (CASABONA, 2006, p. 79-80). A Declaração proíbe a chamada clonagem terapêutica, caracterizada pela transferência do núcleo de uma célula somática em um ovócito previamente enucleado. Casabona destaca, porém, que diversos grupos científicos têm direcionado seus estudos para a obtenção de células-troncos embrionárias utilizando, justamente, essa técnica de transferência nuclear. Nesse contexto, é interessante perceber como, à época, Casabona não considerava que essa técnica era urgente, nem acessível à curto prazo, mas afirmava que não se devia duvidar dos rápidos avanços científicos em genética (CASABONA, 2006, p.80-82), olhar atento que permite contribuir para a construção conceitos imediatos ou futuros, como as nuances que envolvem, hoje, a edição genética.

Ao tratar sobre células-tronco, Casabona apresenta o embrião obtido in vitro por reprodução sexuada como aquele oriundo da fecundação laboratorial de um ovócito por espermatozoide, como ocorre nas técnicas de reprodução assistida. Por outro lado, o embrião obtido por transferência nuclear, através da clonagem terapêutica, é formado a partir da transferência do núcleo de uma célula somática a um ovócito previamente enucleado (CASABONA, 2006, p.88-89). Como consequência da execução das manipulações biológicas, é necessário construir um estatuto jurídico em prol da proteção embrionária. Relata Carlos Casabona que três hipóteses podem ser consideradas: a) o embrião como dotado de um valor próprio, uma vez que ali existe uma pessoa em potencial que deve usufruir da mesma proteção de uma pessoa natural; b) a proteção da vida pré-natal não deve ser superior ao desejo da mãe, de maneira que o embrião in vitro, por exemplo, não teria nenhuma proteção especial caso outros interesses - individuais ou coletivos - estejam em pauta; c) uma posição intermediária, na qual o embrião in vitro tem valor e precisa ser protegido, mas esse valor deve ser contrabalanceado por outros valores (CASABONA, 2008, p.142-143).

As considerações de Casabona sobre a adequação de uma proteção da vida humana em sua dimensão inicial são fundamentais para a aferição do status jurídico do embrião. Sempre buscando a intersecção entre elementos biomédicos, éticos e jurídicos, Casabona tem como uma de suas principais características a preocupação metodológica em diferenciar conceitos complexos, que muitas vezes se assemelham, mas que têm finalidades e implicações éticas distintas.

A edição genética não se confunde com outros procedimentos, como engenharia genética ou clonagem, consubstanciando-se como uma espécie de terapia genética ou gênica. 
Quando se observa temporalmente os diversos temas oriundos da genética que já foram - e ainda são - discutidos por bioeticistas e geneticistas, nota-se que a edição genética é resultado do aprofundamento da pesquisa e do aperfeiçoamento gradual das técnicas de interferência no genoma humano.

Edição genética, como explica Lacadena (2017, p. 3), é uma técnica que proporciona a inserção, eliminação ou substituição de uma molécula de DNA no genoma de um indivíduo, se valendo, para tanto, de enzimas nucleases chamadas de "tesouras moleculares". O procedimento ocorre através da utilização dessas enzimas para quebrar, em locais préestabelecidos, a cadeia dupla que compõe o DNA. Uma vez feitas essas quebras, mutações controladas são promovidas por meio da reparação celular, utilizando, para tanto, mecanismos de união de extremos não-homólogos ou mediante reparação dirigida por homólogos (BERGEL, 2017, p. 455).

Pode-se dizer que a edição genética ocorre em três etapas: identificação, seção e reparação. Inicialmente, estabelece-se um alvo mediante o reconhecimento da sequência da molécula de DNA que será editada. Após a definição do local, realiza-se o corte - a quebra da cadeia dupla por meio da “clivagem”. Em seguida, efetiva-se a edição através da regeneração molecular. Todo esse procedimento ocorre por meio da utilização das enzimas nucleases, que são modificadas de acordo com o interesse do pesquisador (FURTADO, 2019, p. 224).

O próprio conceito de edição genética já é revolucionário, mas é através do advento da tecnologia CRISPR/Cas9 que se tem o estabelecimento de um novo paradigma científico. $\mathrm{O}$ CRISPR/Cas9 faz parte de um sistema de defesa das bactérias contra ataques virais e é composto por dois elementos. O elemento CRISPR (onde a sigla significa “Clustered Regularly Interspaced Short Palindromic Repeats”) ou Repetições Palindrômicas Curtas Agrupadas e Regularmente Interespaçadas é formado por uma molécula de ácido ribonucleico (RNA) sequenciada complementarmente à determinada molécula de DNA-alvo. É por conta desse aspecto complementar que o CRISPR consegue delimitar o local onde o corte será feito. A partir disso, vem à tona o Cas9, segundo elemento do sistema. Trata-se de uma enzima endonuclease que realiza o corte da molécula de DNA no local estabelecido anteriormente pelo CRISPR (BERNARDO-ALVARÉZ, 2017, p.5). Percebe-se, então, que o sistema CRISPR/Cas9 é formado por elementos capazes de colocar em prática duas fases fundamentais da edição genética: identificar o alvo e seccioná-lo.

O procedimento de edição genética pode ocorrer em células germinativas ou células somáticas. As células germinativas têm caráter reprodutivo, estando presentes nos gametas óvulos e espermatozoides. Qualquer alteração genética realizada neste tipo celular, mesmo com 
finalidade terapêutica, é transmitida para a descendência. Isso não ocorre nas células somáticas, por exemplo. Em virtude do seu caráter meramente constitutivo, modificações genéticas em células somáticas não são transmitidas para a descendência (FURTADO, 2019, p. 224).

Essa nova tecnologia é considerada revolucionária, dentre outras coisas, por conta de quatro características fundamentais: a especificidade das modificações induzidas na moléculaalvo, a facilidade de produção e a eficiência no resultado, a acessibilidade técnica e econômica, e a versatilidade de sua utilização (SANTALÓ, 2017, p. 159). A utilização do CRISPR/Cas9 permite controlar melhor as recombinações genéticas, com maior conservação das células, mesmo com o alto grau de mutabilidade no processo de regeneração celular em virtude da perda de nucleotídeos. Em virtude desse maior controle, torna-se possível se valer da edição genética para corrigir mutações, inserir novos genes, trocar bases concretas, além de silenciar ou ativar determinadas informações, dentre inúmeras outras aplicações (MARFANY, 2019, p. 19).

Nessa nova era da Genética, o sistema CRISPR/Cas9 revoluciona a forma de se realizar edição genética, já que consiste em um instrumento de edição mais democrático e com maior alcance. Além disso, sua utilização terapêutica contribui significativamente para avanços médicos, uma vez que um dos seus benefícios é o aperfeiçoamento de terapias genéticas e celulares (FURTADO, 2019, p. 225).

Pesquisas envolvendo procedimentos terapêuticos através de melhorias genéticas já são realidade (GÜELL, 2019, p. 8). As áreas médicas beneficiadas por essas novas modalidades de terapia são as mais variadas: infectologia, oncologia, hematologia, neurologia, transplante de órgãos (MAEDER; GERSBACH, 2016). Ainda, a terapêutica baseada em edição genética viabiliza tanto o tratamento de doenças em curso, quanto a prevenção de patologias futuras. Essa vertente terapêutica da edição genética é, inclusive, uma das vantagens dos avanços biotecnológicos de forma geral (CASABONA, 2002, p. 286).

Diferentemente da edição, a engenharia genética deve ser concebida como a possibilidade ampla de alteração da constituição natural do DNA, através da manipulação, produção e modificação de moléculas do gene, possuindo uma margem de consequências que podem ter como fundamentos finalidades diferentes. A terapia gênica ou genética é conduta que visa a inserção de genes nas células para fins estritamente terapêuticos, de modo que "o conhecimento dos genes responsáveis por características normais ou patológicas permite a plena aplicação dos princípios da medicina genômica, que deverá modificar os procedimentos médicos no diagnóstico e tratamento de várias doenças e onde se inclui a terapia gênica” (NARDI; TEIXEIRA; SILVA, 2002, p.110). 
A conduta envolve a introdução, no paciente portador da doença, “de genes responsáveis por proteínas que poderão ser benéficas. Em doenças causadas por mutações gênicas, a introdução de um gene normal poderá reverter o quadro clínico” e, “em uma ampla gama de outros tipos de doenças, células geneticamente modificadas poderão ativar mecanismos de defesa naturais do organismo (como o sistema imune) ou produzir moléculas de interesse terapêutico”. (NARDI; TEIXEIRA; SILVA, 2002, p.110). A edição genética está, pois, situada como uma técnica específica de terapia gênica.

Partindo então da função terapêutica da edição genética, esse estudo passa a pensar a utilização dessa técnica no âmbito dos sistemas de saúde brasileiros, tanto no que se refere à cobertura do Sistema Único de Saúde quanto à cobertura da Saúde Suplementar. Para tanto, analisa aspectos bioéticos e jurídicos que devem ser levados em conta quando se pretende estabelecer critérios e diretrizes basilares para uma temática pouco conhecida e normativamente não disciplinada.

\section{A EDIÇÃO GENÉTICA COMO REALIDADE POSSÍVEL: A COBERTURA À LUZ DO SISTEMA ÚNICO DE SAÚDE E DA SAÚDE COMPLEMENTAR}

Em 25 de abril de 1953, os cientistas James Watson e Francis Crick publicam na revista científica Nature um trabalho que mudaria para sempre o conhecimento sobre a genética humana: o descobrimento da dupla hélice da molécula de DNA. Essa descoberta permite conhecer a estrutura do DNA e, consequentemente, entender como é a constituição e funcionamento da vida biológica. A pesquisa de Watson e Crick é o alicerce para o desenrolar da engenharia genética, que, cada vez mais, se afasta do plano teórico e se insere de forma prática nas vidas das pessoas (WATSON; CRICK, 1953).

De acordo com a geneticista Gemma Marfany (2019, p.22), os níveis de incidência de doenças genéticas hereditárias, quando consideradas em conjunto, atingem entre 6\% e 8\% da população. Por conta disso, o desenvolvimento das técnicas de edição genética, bem como sua utilização terapêutica, envolve uma questão sanitária e social. Os impactos das doenças genéticas para a sociedade são reiterados e relevantes, o que enseja a busca pelo fomento da prática da técnica e a busca pelas alternativas quanto à sua acessibilidade.

A edição genética, não obstante ser instrumento fundamental perante o tratamento de patologias genéticas, evidencia a possibilidade de modificação da própria natureza humana (SANDEL, 2018, p.19). Essa afirmação chama a atenção para a notória preocupação bioética diante da possibilidade constante de manipulação da vida. Isso porque, embora a sua finalidade 
terapêutica possa ser eticamente aceita, não se pode deixar de considerar a possibilidade de utilização da edição genética para fins de aperfeiçoamento genético - ou enhancement.

Independentemente dos inegáveis benefícios terapêuticos decorrentes da manipulação das moléculas de DNA através da edição genética, a adoção plena dessa técnica ainda causa receios, seja na esfera bioética ou na científica. Enquanto a natureza médica dos avanços em genética desponta como novos caminhos, o medo social advindo da ascensão de fatos desconhecidos cresce paralelamente (MEIRELLES, 2017, p. 3). Esses fatos desconhecidos, por sua vez, são oriundos da possibilidade de aperfeiçoamento ou melhoramento genético com finalidades não terapêuticas. Segundo Gemma Marfany (2019, p.22), esse "melhoramento genético” consiste em modificações voltadas à obtenção de determinados fenótipos. Ou seja, características físicas, intelectuais e até mesmo comportamentais que, em alguma medida, são mais atrativas, segundo o olhar de determinada pessoa ou determinado grupo social.

Um dos cernes da técnica está na diferenciação entre a utilização da edição genética para fins terapêuticos ou para o chamado melhoramento. Há uma linha tênue entre essas duas acepções que dificulta a liberação segura da conduta. É justamente essa sutileza intrínseca à motivação da conduta que imprime complexidade à discussão bioética sobre o assunto (MEIRELLES, 2017, p.5). A ideia de aperfeiçoamento ou melhoramento está relacionada à uma lógica de mercado e a uma demanda segregacionista, que cria padrões fenotípicos ideais (HABERMAS, 2004, p.27).

O debate bioético envolvendo as finalidades do uso da edição genética é fundamental para o desenvolvimento adequado dessa tecnologia. Entretanto, deve-se ter como ponto preliminar que a manipulação voltada ao chamado “aperfeiçoamento genético” ainda não é possivelmente concretizável. Segundo Audrey Chapman (2019, p.22), as pretensões de aperfeiçoamento estão relacionadas à uma alta complexidade genética, ainda pouco viável em termos pragmáticos. O uso terapêutico da edição genética, por sua vez, já é uma realidade. Em 2016, por exemplo, pesquisadores publicaram um estudo demonstrando sucesso na correção do gene da hemoglobina que causa a anemia falciforme através do CRISPR/Cas9 (DEWITT; MAGIS; BRAY; et al., 2016).

A edição genética voltada ao tratamento de patologias graves tem representado um grande passo em prol da humanidade no que diz respeito à saúde. Pode-se então pensar na necessidade de uso terapêutico da edição genética, considerando sua aplicação no âmbito da saúde no Brasil, seja através do Sistema Único de Saúde (SUS) ou por meio da saúde suplementar. 


\subsection{Edição genética e princípio da universalidade da cobertura}

A Constituição Federal, em seu artigo 196, determina que “a saúde é dever de todos e dever do estado” (Brasil, 1988). Esse comando programático, versando sobre um direito fundamental, é considerado elemento basilar do sistema público de saúde brasileiro, o Sistema Único de Saúde ou SUS. O conteúdo desta norma constitucional traz o princípio mais importante desse sistema - o princípio da universalidade da cobertura (ANDRADE; ANDRADE, 2010, p. 67).

Com a promulgação da lei $n^{\circ}$ 8.080/1990, o princípio da universalidade foi efetivamente positivado. Nesse sentido, o inciso I do artigo $7^{\circ}$ da referida lei dispõe sobre a "universalidade de acesso aos serviços de saúde em todos os níveis de assistência” (BRASIL, 1990). Já o inciso II do mesmo dispositivo determina a "integralidade de assistência, entendida como conjunto articulado e contínuo das ações e serviços preventivos e curativos, individuais e coletivos, exigidos para cada caso em todos os níveis de complexidade do sistema” (BRASIL, 1990). É a partir dessa legislação que o Brasil passou, de fato, a ter um sistema público de saúde único e universal.

O princípio da universalidade estende o direito de acesso à saúde a todas as pessoas. Esse acesso, por sua vez, deve ser integral. Em outras palavras, na prática, o SUS deve proporcionar e disponibilizar serviços de saúde variados para todos os indivíduos, de forma contínua e adequada às variadas necessidades, sem qualquer discriminação. É assim que se compreende a ideia de saúde como direito de todos e dever do Estado. Pelo argumento da universalidade, mesmo que a pessoa opte pela utilização do sistema suplementar, através de planos privados de saúde, o direito de utilizar o SUS permanece intacto.

No entanto, segundo Salvador Bergel, o direito à saúde é estigmatizado pela ineficácia, em muitas situações, em virtude de "problemas concretos de natureza conceitual” (BERGEL, 2006, p. 145). Nesse contexto, à Bioética cabe o papel de construir diretrizes que resultem na materialização de aspectos científicos, éticos e morais nas vidas das pessoas. Ao tratar da interferência da Bioética no campo político, Bergel afirma que "é necessário reconhecer que as políticas econômicas e sociais estão indiscutivelmente ligadas à sua esfera de interesse” (BERGEL, 2006, p. 142). Assim, cumpre à Bioética, a partir de suas diretrizes principiológicas, contribuir para a construção adequada dos fundamentos que garantam o acesso à saúde em sua dimensão eficaz.

Quando se fala de edição genética terapêutica no âmbito do SUS, é preciso ter em voga o embasamento principiológico que fundamenta esse sistema de saúde, que o torna aberto à 
ideia de dinamicidade na perspectiva das coberturas. De acordo com Borges e Schumacher (2013, p.48), “a busca pela universalidade e equidade do SUS passa necessariamente pela ponderação entre os interesses individuais e os coletivos”. Assim sendo, o princípio da universalidade não apenas estende o atendimento a todos, mas ajuda na constituição de diretrizes de eficiência do sistema de saúde. A edição genética, por sua vez, pode ser importante instrumento para a consubstanciação do direito à saúde e, portanto, deve passar, enquanto alternativa terapêutica, a integrar o rol de cobertura do sistema público de saúde.

Os avanços da genética após o advento do CRISPR/Cas9 devem revelar a recepção do argumento democrático, concretizado pelo direito de acesso às tecnologias e ferramentas disponíveis em escala global em prol da garantia de direitos fundamentais. Antes do surgimento da técnica, realizar edição genética era caro e complicado. A utilização de meganucleases, por exemplo, demanda aproximadamente entre 4 e 5 anos de trabalho, custando em torno de $€$ $6.000,00$. As nucleases zinc-finger, por sua vez, custam perto de $€ 30.000,00$ durante o processo. Já o sistema CRISPR/Cas9, durante as 2 ou 3 semanas de trabalho necessárias, custa apenas em torno de $€$ 30,00 (LACADENA, 2017, p.3).

A diferença de custo-benefício entre as técnicas de edição genética mencionadas é gigantesca. Diferença essa que se torna ainda mais flagrante se considerada à luz de um sistema de saúde que precisa acolher milhões de pessoas. O pouco tempo de trabalho necessário para realização da edição, bem como seu baixo custo, fazem do CRISPR/Cas9 instrumento terapêutico com diferencial. Isso sem contar o grande número de pessoas portadoras de patologias genéticas. Nesse sentido, a partir do momento em que a edição genética se consolidar como ferramenta terapêutica dessas patologias, torna-se fundamental que o SUS incorpore o procedimento e o disponibilize.

As vantagens são diversas: a principal é a melhora da qualidade de saúde das pessoas, vez que será proporcionado tratamento eficiente para patologias sérias. Além disso, haverá menor custo para o tratamento em comparação com outras alternativas. Em 2017, por exemplo, o Ministério da Saúde indicou o uso de larodinase como terapia de reposição enzimática na mucopolissacaridose tipo I (patologia genética rara), estimando gastos entre R 29.000 .000 e R\$ 44.000.000 (BRASIL, 2017). O uso de terapia genética, além de proporcionar redução de gastos, poderá contribuir para a diminuição do ajuizamento de ações pleiteando tratamentos de alto custo para essas patologias, o que também representa benefício de ordem econômica que pode ser revertido em melhorias do próprio SUS.

O SUS tem o objetivo de garantir o acesso à saúde de forma universal, integral e igualitária. Porém, uma de suas principais críticas diz respeito à dificuldade desse sistema em 
promover justiça social em uma sociedade tão desigual quanto a brasileira. A implementação da edição genética terapêutica no âmbito do SUS precisa ser realizada em conjunto com ações voltadas à diminuição dessas diferenças sociais no acesso à saúde. Essas ações devem englobar a distribuição de recursos, oportunidades de acesso e utilização dos serviços (COBUCCI; DUARTE, 2013, p. 63).

Adotar técnicas de edição genética, em especial o sistema CRISPR/Cas9, pode representar a utilização racionalizada de recursos. Porém, mais importante do que isso, é o aspecto funcional da edição genética. Trata-se de modalidade eficiente, abrangente e barata. Logo, sua adoção está relacionada à efetivação do acesso à saúde, colocando à disposição da sociedade alternativas terapêuticas eficazes e acessíveis, na medida em que os resultados podem ser promissores.

\subsection{Edição genética e saúde suplementar}

O sistema de saúde brasileiro é fundamentado na Constituição Federal e regulamentado através da Lei $n^{\circ}$ 8.080/1990, que possibilita a participação da iniciativa privada no SUS em caráter complementar ou suplementar (BRASIL, 1990). Nesse sentido, a Saúde Complementar é constituída pela atuação de planos e seguros de saúde privados. Para regular a Saúde Complementar, foram elaboradas a lei n ${ }^{\circ}$ 9.656/1998, que dispõe sobre os planos de saúde, e a lei $n^{\circ}$ 9.961/2000, que instituiu a Agência Nacional de Saúde Complementar (ANS). Além disso, tem-se a lei $\mathrm{n}^{\circ}$ 8.078/1990, o Código de Defesa do Consumidor, que é utilizado subsidiariamente para solução de conflitos envolvendo operadoras e contratantes. Ainda, temse as normas infralegais expedidas pela própria ANS. Esse arcabouço normativo compõe a regulamentação da Saúde Complementar (ou suplementar) no Brasil (ANTONIO, 2018).

O uso da edição genética terapêutica corrobora a efetivação do direito ao acesso à saúde. Sendo assim, se essa aplicação deve ser englobada pelo SUS, também deve ser objeto de cobertura dos planos de saúde privados. Em setembro de 2019, um grupo de pesquisadores da Universidade de Pequim relatou testes com CRISPR/Cas9 em um homem de 27 anos com leucemia e portador do vírus HIV (XU; WANG; LIU; et al., 2019). Os pesquisadores se valeram da tecnologia de edição genética para inativar o gene que viabiliza a entrada do HIV nos linfócitos, antes do transplante de medula. O experimento obteve sucesso parcial e, cerca de um ano e meio depois, a leucemia continuou em remissão e a medula transplantada continuou produzindo linfócitos saudáveis, mesmo em pouca quantidade. (XU; WANG; LIU; et al., 
2019). É importante perceber o grau de segurança que a utilização do CRISPR/Cas9 apresentou, o que reforça a sua relevância terapêutica.

O que se pretende demonstrar é como a plena utilização da edição genética para o tratamento de patologias é uma questão de tempo. Conforme pressupôs Thomas Kuhn (1998, p.47), um dos focos da dita "ciência normal” é o trabalho de articulação dos paradigmas concretizados pelos cientistas. Em outras palavras, a Ciência está sempre trabalhando para trazer soluções aos problemas apresentados por um novo paradigma, mas que ainda não foram enfrentados. Isso significa que, em alguns anos, a tecnologia CRISPR/Cas9 deixou de ser experimental e passa a ser indicada terapeuticamente. A proposta da edição genética pode representar então uma mudança de paradigma - o rompimento com tratamentos predecessores tradicionais não eficazes em prol da incorporação de novo protocolo terapêutico.

Nesta discussão, não parece razoável afirmar que as despesas com CRISPR/Cas9 consistem em empecilhos à sua utilização terapêutica. Outras técnicas de edição genética, conforme abordado acima, de fato têm altos custos que impedem sua plena utilização. Porém, o CRISPR/Cas9 é tão acessível que é possível encontrar na internet vídeos ensinando como utilizar a técnica (LEDFORD, 2015). Além disso, o custo da técnica possibilita sua utilização para testagem de infectados pelo Novo Coronavírus (DING; YIN; LIU, 2020). Essas funcionalidades demonstram a necessidade de garantir o processo de democratização científica através da acessibilidade global da técnica.

Não obstante, a incorporação da edição genética no Brasil passa pela diferença entre os serviços de saúde prestados no âmbito do SUS e na esfera dos planos de saúdes privados. Conforme destaca Cobucci e Duarte (2013), essa diferenciação acentua as desigualdades em saúde, já que há flagrante divergência entre o tratamento de saúde recebido entre quem pode pagar e quem não pode. Além disso, as dificuldades na gestão do SUS, seja ao contratar serviços privados, seja na oferta desordenada de assistência médica ambulatorial, acabam favorecendo “a concentração de atendimentos a uns indivíduos em detrimento de outros” (COBUCCI; DUARTE, 2013, p. 64).

A regulação envolvendo edição genética e seus desdobramentos é incipente. A Lei $\mathrm{n}^{\mathrm{o}}$ 11.105/2005 (BRASIL, 2005), que trata sobre a biossegurança no âmbito dos organismos geneticamente modificados, é insuficiente para abarcar todos os desdobramentos necessários. Parte dessa insuficiência diz respeito ao seu contexto e momento de criação. O objeto da referida lei é regular a produção e comercialização de organismos transgênicos e as pesquisas científicas envolvendo células-tronco. Sua importância temática é inegável e coaduna as necessidades de sua época de promulgação (2005). 
Porém, a ciência é dinâmica e hoje os problemas da genética vão muito além de alimentos transgênicos e estudos com células-troncos. Para que a edição genética possa ser instrumento terapêutico incorporado pelo sistema de saúde brasileiro, seja público ou privado, faz-se necessário a consolidação de disciplina normativa que apare e regulamente as condutas e consequências que podem estar relacionadas à prática.

\section{AS IMPLICAÇÕES BIOÉTICO-JURÍDICAS DA EDIÇÃO GENÉTICA COMO ALTERNATIVA TERAPÊUTICA}

O uso da edição genética tem apresentado sucesso terapêutico no enfrentamento de patologias graves incuráveis e de difícil trato. Por outro lado, surge a preocupação de que a técnica possa ser usada para fins de aperfeiçoamento genético. Nesse contexto, torna-se imprescindível ponderar fundamentos bioéticos e jurídicos em prol de orientar a realização adequada do procedimento de edição.

Tradicionalmente, a espécie humana se autocompreendia a partir de uma constituição genética natural e casual de elementos não domináveis. Assim, a autocompreensão da espécie era interpretada a partir da ideia do aleatório, manifestada pela fusão de patrimônios genéticos que se encontraram casualmente (HABERMAS, 2004, p.17). A ruptura de paradigma com a forma com que o ser humano se autocompreendeu ao longo dos tempos está, justamente, na admissibilidade das técnicas que envolvem a interferência desse processo aprioristicamente natural, como a clonagem, a engenharia genética e a terapia genética, onde estão situados os processos de edição genética.

Essa capacidade de interferência nas características naturais da espécie tem aptidão para transformar significativamente a autocompreensão humana. O que antes era percebido como algo natural e imutável passa a ser compreendido como uma possibilidade de manifestação genética que pode ter sido manipulada. Essa nova realidade, por sua vez, representa mudança na compreensão existencial do ser humano sobre si mesmo e necessita, pois, de auxílio da Bioética e do Direito, como áreas auxiliares à conformação da proteção adequada aos sujeitos envolvidos (MEIRELLES, 2017, p.3).

Ao ser humano passa a ser possível escolher e selecionar genes. Essas escolhas, conforme Habermas (2004, p. 27), envolvem um espectro volitivo onde estão contidos o viés terapêutico e a intenção de aperfeiçoamento ou melhoramento. O que pode prevalecer, então, são as intenções individuais dos integrantes do mercado, e, por isso, a necessidade de pensar a edição genética a partir do recorte puramente terapêutico. 
A extensão da disponibilização de tratamentos médicos fundamentados em edição genética deve ocorrer de forma universal. Para tanto, no Brasil, tratamentos médicos baseados em edição genética precisam ser acessíveis à coletividade equitativamente. Entretanto, a estrutura do SUS é maculada por mazelas que dificultam a efetivação da equidade na assistência médica. Uma dessas mazelas é a distribuição desigual das unidades de saúde entre as regiões e os Estados.

Conforme destaca Cobucci e Duarte (2013, p. 64), a grande concentração de estabelecimentos médicos cadastrados fica na região Sudeste e nas grandes cidades. Essa desigualdade fica mais clara quando analisada juntamente com a cobertura do sistema de saúde suplementar, usado por mais 40 milhões de brasileiros.

A desigualdade na saúde é um grande obstáculo para a incorporação de técnicas terapêuticas promissoras. Consequentemente, a população é prejudicada, pois deixa de ter acesso a tratamentos mais adequados e inovadores por conta da má gestão de políticas públicas. Por outro lado, o sistema complementar também apresenta limitações ao acesso à saúde, já que “é excludente com a criação de regras como doença preexistente e período de carência, fazendo com que seus usuários muitas vezes necessitem utilizar os serviços do SUS” (COBUCCI; DUARTE, 2013, p. 64).

As implicações da edição genética e o seu potencial transformador envolvem conflitos que podem ser refletidos sob o viés de diversos direitos fundamentais, como a saúde, a liberdade de investigação científica ou a dignidade da pessoa humana (BERNARDO-ÁLVAREZ, 2017, p.12). Assim sendo, a efetivação do uso terapêutico da técnica demanda cuidados. Esses cuidados, por sua vez, devem ser voltados tanto à segurança do procedimento quanto aos elementos que justificam sua utilização. Essa proteção, voltada especificamente para a edição genética terapêutica, no que diz respeito ao pressuposto regulatório, é inexistente no Brasil.

A lei ${ }^{0} 11.105 / 2005$, apesar de tratar de aspectos da genética, é muito limitada. A lei não esclareceu quais tipos de manipulações gênicas são proibidas - o que deixa dúvida acerca do uso de terapias genéticas. "Há quem entenda que a vedação é apenas quanto às condutas que modifiquem a estrutura do DNA, excluindo do dispositivo a terapia gênica celular, que tem como proposta sanar enfermidades genéticas diagnosticadas” (MEIRELLES, 2017, p. 8).

Diante da ausência de regulação específica para uma questão tão fundamental, torna-se imprescindível legislar sobre o assunto. A lei, então, deve se valer de critérios bioéticos a fim de promover a segurança e aplicabilidade necessária à implementação da edição genética como protocolo terapêutico no sistema de saúde. 
Os cuidados em saúde envolvendo edição genética já fazem parte do debate bioético no mundo. Instituições de renome têm discutido o assunto e pensado diretrizes. Essas orientações são fundamentais para alicerçar a utilização da edição genética no sistema de saúde brasileiro. Nesse sentido, National Academies of Sciences, Engineering, and Medicine produziram o relatório "Human Genome Editing: Science, Ethics and Governance" (NATIONAL ACADEMIES OF SCIENCES, ENGINEERING, AND MEDICINE, 2017). O objetivo é promover aplicações da edição do genoma humano voltadas à saúde e ao bem-estar dos indivíduos, seja através da prevenção ou do tratamento de doenças.

O debate bioético sobre a implementação da edição genética terapêutica também se destaca na Europa. Nesse sentido, os espanhóis Josep Santaló e María Casado elaboraram o “Documento sobre bioética y edición genómica en humanos”, para também estabelecer diretrizes na utilização dessa ferramenta (SANTALÓ; CASADO, 2016). Nesse relatório, é destacada a velocidade de aplicação das técnicas de edição genômica em humanos. Como exemplo, destacam os experimentos voltados à cura do câncer de pacientes graves e sem tratamentos disponíveis (SANTALÓ; CASADO, 2016, p. 27). Nesse sentido, concebe como admissível a utilização da edição genética em células somáticas (que não são transmitidas hereditariamente) tanto para cultivo e investigação básica, quanto para terapia genética de pacientes.

Juan Rámon Lacadena (2017, p.9) aponta critérios bioéticos fundamentais a serem observados quando se trata de edição genética. O primeiro desses critérios é, justamente, a aplicação da terapia genética apenas voltada ao tratamento de pacientes com patologias genéticas específicas, rechaçando-se absolutamente qualquer conduta eugênica de melhoramento do genoma humano.

Como preocupação decorrente da prática da edição, surge a questão neoeugênica. Na história da humanidade, a eugenia revelava um ideal de perfeição perseguido que justificava ações para impedir o nascimento, a sobrevivência ou a reprodução de seres considerados “imperfeitos”, valendo-se de métodos como "eutanasia neonatal, aborto o esterilización de individuos considerados atávicos o mentalmente anormales” (CASABONA, 2002, p. 288). Sabe-se que, na atualidade, "los análisis genéticos preconceptivo, preimplantatorio y prenatal son un instrumental precioso que aporta la ciencia, pero que pueden ser utilizados en favor de estas corrientes, que han resurgido en la actualidad como la "nueva eugenesia” o "neoeugenesia [...]” (CASABONA, 2002, p. 288). A possibilidade de acessar a informação genética, seja por diagnósticos ou por técnicas como a edição, aponta para a preocupação sobre o risco de permitir 
que determinadas características sejam selecionadas e introduzidas em um indivíduo ainda não nascido (CASABONA, 2007, p. 108).

Resta consolidada a primeira diretriz bioética fundamental da admissibilidade da edição genética: a necessidade de contingenciar o seu uso para fins estritamente terapêuticos e que, portanto, tenha como precedente a aferição diagnóstica exata da doença e a justificativa para a pertinência da técnica.

Apesar de gozar de boa aceitação pela comunidade científica, a edição genética terapêutica, quando utilizada, deve observar a ausência de alternativas médicas ou, havendo outras alternativas, a consideração de que essas sejam demasiadamente perigosas. A terapia genética deve ser restrita à edição em células somáticas, o que, inclusive, revela menores problemas éticos. As células somáticas, diferentemente das germinativas, são células do corpo da pessoa, portanto, estruturas celulares já desenvolvidas (LACADENA, 2017, p.9).

Outra diretriz bioética decorre, então, da pressuposição descrita. É necessário restringir a prática da edição às células somáticas (e, portanto, já desenvolvidas), excluindo a realização da terapia em células germinativas, com vistas à preservação da naturalidade do patrimônio genético e à manutenção de maior margem de segurança à saúde da descendência.

A regulação da terapia genética é importante e necessária para o aperfeiçoamento dos sistemas de saúde. Na Europa, o órgão responsável pelo assunto é a Agência Europeia de Medicamentos (EMA). Já nos Estados Unidos, a temática é de responsabilidade da U.S Food and Drug Administration (FDA). Baseadas nos rápidos avanços terapêuticos que decorrem das novas tecnologias, essas agências estão voltadas ao estabelecimento de novas diretrizes que permitem auxiliar os processos decisórios envolvendo os experimentos clínicos. Nesse sentido, EMA e FDA trabalham juntas para alinhar as diretrizes e evitar divergências (BENDER, 2018).

A identificação e proteção dos bens jurídicos envolvidos na edição genética é fundamental para a própria efetivação dos direitos humanos. Casabona entende que os direitos relacionados ao genoma humano e às biotecnologias se originam de uma "soft law”, "normas jurídicas no esencialmente obligatorias ni coercitivas, sino más bien exhortativas” (CASABONA, 2002, p. 290). Porém, para o autor, é fundamental compreender que o direito constitucional se mostra como elemento materializador desses direitos, estando nele os fundamentos necessários para a investigação e limitação da prática das condutas relacionadas à genética. 
Revista da Faculdade Mineira de Direito |V.23 N.46|

Dossiê "O Direito e a Bioética ante os limites da Vida Humana em Carlos María Romeo Casabona"

emergen, de lo que encontramos numerosos ejemplos en el constitucionalismo comparado moderno (CASABONA, 2002, p.291).

As contribuições de Carlos Maria Romeo Casabona revelam alcance universal, considerando os aspectos transcultural e multidisciplinar propostos nos seus escritos. Ao tratar sobre investigações e manipulações genéticas, Casabona pondera o fato de que os benefícios reais e virtuais são bastante conhecidos, sendo imprescindível a adoção de medidas protetivas e de cuidados quando esses procedimentos envolvem seres-humanos (CASABONA, 2005).

\begin{abstract}
No obstante, la elaboración de procedimientos y productos biotecnológicos y las investigaciones que la sustentan deben ser compatibles con la adopción de precauciones y medidas de seguridad en el manejo de la materia viva, más todavía cuando ésta ha sido objeto de modificaciones genéticas, cuyas interferencias en otros seres vivos, incluido el ser humano, son todavía impredecibles (ROMEO CASABONA, 2005, p. 3).
\end{abstract}

Nesse contexto, a imparável expansão do fenômeno da globalização demanda a busca de pontos de equilíbrio frente aos graves riscos que podem derivar das fontes de poder que estão além do controle dos Estados ou da Comunidade Internacional. Assim, a biotecnologia é uma das mais “atractivas tentaciones para pretender sobrepasar cualquier limite” (CASABONA, 2005, p. 4) e os direitos humanos e fundamentais devem ser os instrumentos adequados para a conformação dessa barreira.

Os direitos humanos devem ser concebidos como elementos de desenvolvimento internacional de alguns princípios bioéticos, o que é importante para integração transcultural. O desafio dos tempos atuais é assegurar que a globalização ética e jurídica se dê num contexto de transculturalidade que envolva "una aceptación universal de ciertos valores y derechos compartidos que sean capaces de dar las respuestas exigidas por los desafíos de un mundo globalizado” (CASABONA, 2005, p. 4).

Essa valorização dos direitos humanos é fundamental e deve ser concebida como elemento de vinculação entre o direito internacional e o direito interno dos Estados, em especial no âmbito das ciências biomédicas:

Como se ha podido comprobar, no pocos de estos principios a su vez se han ido configurando también en el Derecho Internacional y son de extraordinaria importancia para lograr enfoques adecuados en relación con las ciencias biomédicas; es decir, una interacción del Derecho Internacional y el Derecho Interno cada vez más frecuente y profunda (CASABONA, 2002, p. 291). 
A edição genética se relaciona evidentemente com essa noção de ciência globalizada. Os impactos e as implicações do uso da edição genética, que é uma técnica capaz de transformar a própria autocompreensão do ser humano, demandam reflexões universais, já que o patrimônio genético da humanidade é um bem global e deve ser efetivamente protegido. Nesse sentido, a identificação de problemas e a proposição de soluções, pautadas em diretrizes bioéticas e nos direitos humanos, é de grande valia, e devem ser recepcionadas para além de normativas internacionais, demandando regulações internas.

\section{CONCLUSÃO}

O surgimento da tecnologia CRISPR/Cas9 revoluciona a edição genética e traz novos horizontes ao tratamento das patologias humanas graves. As evidências científicas publicizadas apontam para o fato de que a utilização terapêutica da edição genética tem potencial para melhorar a qualidade da saúde e vida das pessoas. Por essa razão, é necessário pugnar pela incorporação da técnica aos sistemas de saúde.

Esse estudo demonstrou porque a edição genética deve ser englobada pelo Sistema de Saúde do Brasil, seja no âmbito da saúde pública ou na saúde complementar. À luz do princípio da universalidade da cobertura, a terapia genética pode ser uma alternativa mais eficiente e barata ao tratamento de patologias graves. As dificuldades consoantes à essa implementação perpassam pela grande desigualdade que se manifesta nas relações de saúde no país e pela ausência de legislação sobre a técnica, já que a lei 11.105/2005 é incipiente e não contempla diversos assuntos relacionados à terapia genética. Sabe-se que muitos outros tratamentos também devem ter cobertura imediata pelo sistema público e privado, posto estarem frontalmente interligados à possibilidade de sobrevida dos pacientes.

A aplicação benéfica da edição genética exige enfrentamento de problemas como a segurança dos indivíduos submetidos à terapia, além das desigualdades socioeconômicas no âmbito das relações de saúde. Em virtude da carência legislativa sobre o tema, faz-se primordial o estabelecimento de diretrizes e critérios bioéticos, como já realizado em países que adotam protocolos de terapia genética, que auxiliem a adequada implementação dessa nova tecnologia, evitando práticas neoeugênicas e garantindo a segurança dos envolvidos.

Nesse contexto, para que a terapia genética se desenvolva e possa auxiliar no melhoramento da saúde do Brasil, torna-se imprescindível estabelecer sua adequada regulação. A ausência de disciplina normativa, somada ao contexto de desigualdade em saúde, são obstáculos à efetivação de direitos fundamentais. A disciplina legal deve ter como pauta 
critérios bioéticos que proíbam práticas eugênicas e interesses puramente mercadológicos e garantam a segurança dos pacientes. Normativas internacionais devem ser diretrizes à constituição do direito interno, na medida em que recepcionaram princípios fundamentais ao uso ético e seguro da informação genética em prol de manter resguardado direitos ínsitos à condição ontológica do ser humano.

O desenvolvimento da terapia genética demanda o estabelecimento de regulação adequada. A norma criada deve priorizar o desenvolvimento e implementação da edição genética em células somáticas, estabelecendo parâmetros de aplicação adequados. Porém, é preciso também limitar a prática da técnica células germinativas, em razão dos impactos na manutenção da naturalidade do patrimônio genético. Por fim, essa regulação deve ser fiscalizada por uma agência reguladora competente que garanta o respeito às diretrizes e aos critérios estabelecidos. Um sistema de saúde eficaz e moderno precisa disponibilizar o melhor que a tecnologia tem a oferecer. Entretanto, o gradativo aperfeiçoamento deve levar em conta as problemáticas do sistema e os dilemas bioéticos inerentes aos avanços científicos.

\section{REFERÊNCIAS}

ANDRADE, Elizabeth Nogueira de; ANDRADE, Edson Oliveira. O SUS e o direito à saúde do brasileiro: leitura de seus princípios, com ênfase na universalidade da cobertura. Revista Bioética, v. 18, n. 1, p. 61-74, 2010. Disponível em: $<$ https://revistabioetica.cfm.org.br/index.php/revista_bioetica/article/view/536>. Acesso em: 04 out. 2020.

ANTONIO, Gilka Lopes Moreira. Planos privados individuais de saúde: o consumidor ainda tem poder de escolha? Caderno Ibero-Americanos de Direito Sanitário, v. 7, n.1, p.163-182, jan/mar 2018.2 Disponível em: https://www.cadernos.prodisa.fiocruz.br/index.php/cadernos/article/view/463. Acesso em: 04 out. 2020.

BENDER, Eric. Regulating the gene-therapy revolution. Nature, n. 564, p. 20-22, 2018. Disponível em: https://www.nature.com/articles/d41586-018-07641-1. Acesso em: 06 out. 2020.

BERGEL, Salvador Darío. Bioética y el derecho de aceso a los medicamentos. Revista de Direito Sanitário, v. 7, n. 1-3, p. 117-162, 2006. Disponível em: http://www.revistas.usp.br/rdisan/article/view/79971 . Acesso em: 06 out. 2020.

BERNARDO-ÁLVAREZ, Maria Ángela. La revolución de CRISPR-Cas9: una aproximación a la edición genómica desde la bioética y los derechos humanos. Revista Iberoamericana de Bioética, n. 3, p. 1-13, 2017. Disponível em: https://doi.org/10.14422/rib.i03.y2017.003. Acesso em: 06 out. 2020. 
BORGES, Danielle da Costa Leite; SCHUMACHER, Mercedes. O equilíbrio entre o individual e o coletivo na busca pela universalidade do Sistema Único de Saúde. Cadernos IberoAmericanos de Direito Sanitário, v. 2, n. 2, p. 36-50, jul./dez 2013. Disponível em: https://www.cadernos.prodisa.fiocruz.br/index.php/cadernos/article/view/66. Acesso em: 06 out. 2020.

BRASIL. Constituição da República Federativa do Brasil de 1988. Disponível em: http://www.planalto.gov.br/ccivil_03/constituicao/constituicao.htm. Acesso em: 06 out. 2020.

BRASIL. Lei 8.080 de 19 de setembro 1990. Dispõe sobre as condições para a promoção, proteção e recuperação da saúde, a organização e o funcionamento dos serviços correspondentes e dá outras providências. Disponível em: http://www.planalto.gov.br/ccivil_03/leis/l8080.htm. Acesso em: 06 out. 2020.

BRASIL. Lei 9.656 de 3 de junho de 1998. Dispõe sobre os planos e seguros privados de assistência à saúde. Disponível em: http://www.planalto.gov.br/ccivil_03/leis/19656.htm. Acesso em: 06 out. 2020.

BRASIL. Lei 11.105 de 24 de março de 2005. Regulamenta os incisos II, IV e V do $\S 1^{\circ}$ do art. 225 da Constituição Federal, estabelece normas de segurança e mecanismos de fiscalização de atividades que envolvam organismos geneticamente modificados [...]. Disponível em: http://www.planalto.gov.br/ccivil_03/_ato2004-2006/2005/lei/l11105.htm. Acesso em: 06 out. 2020.

BRASIL. Ministério da Saúde. Laronidase como terapia de reposição enzimática na mucopolissacaridose tipo I. Brasília, 2017. Disponível em: http://conitec.gov.br/images/Relatorios/2017/Relatorio_laronidase_MPSI_FINAL_293_2017. pdf. Acesso em: 06 out. 2020.

CASABONA, Carlos Maria Romeo. Consideraciones jurídicas sobre las tecnicas geneticas. Anuario de filosofía del derecho, n. 12, p. 15-38, 1995. Disponível em: https://dialnet.unirioja.es/servlet/articulo?codigo=142331. Acesso em: 04 out. 2020.

CASABONA, Carlos Maria Romeo. Consideraciones jurídicas sobre procedimientos experimentales de mejora en neurociencias. In: CASABONA, Carlos Maria Romeo. Más allá de la salud: intervenciones de mejora en humanos. Granada: Comares, 2012.

CASABONA, Carlos Maria Romeo. Bienes jurídicos implicados en la clonación. Revista de derecho y ciencias penales: Ciencias Sociales y Políticas, n. 2, p. 145-168, 2000.

Disponível em: https://rduss.com/index.php/rduss/article/view/310. Acesso em: 04 out. 2020.

CASABONA, Carlos Maria Romeo. Ethical, legal and social issues related to cell therapy. Revista de derecho y genoma humano = Law and the human genome review, n. 28, p. 141158, 2008. Disponível em: https://pubmed.ncbi.nlm.nih.gov/18942509/. Acesso em: 04 out. 2020.

CASABONA, Carlos Maria Romeo. Hacia un Derecho Transcultural para la Genética y la Biotecnología Humanas. Revista de Bioética y Derecho,n. 3, p. 3-8, 2005. Disponível em: https://revistes.ub.edu/index.php/RBD/article/view/7916/9817. Acesso em: 04 out. 2020. 
CASABONA, Carlos Maria Romeo. La clonación humana: los presupuestos para la intervención penal. Revista galega de administración pública, n. 27, p. 127-167, jan-abr 2001. Disponível em: https://egap.xunta.gal/revistas/REGAP/article/download/799/1261/. Acesso em: 04 out. 2020.

CASABONA, Carlos Maria Romeo. La cuestión jurídica de la obtención de células troncales embrionarias humanas con fines de investigación biomédica. Revista de derecho y genoma humano = law and the human genome review, n. 24, p. 75-128, 2006.

CASABONA, Carlos Maria Romeo. La genética y la biotecnologia en las fronteras del derecho. Acta Bioethics, v. 8, n. 2, p. 283-297, 2002. Disponível em: http://dx.doi.org/10.4067/S1726569X2002000200009. Acesso em: 04 out. 2020.

CASABONA, Carlos Maria Romeo. La Ley de Investigácion Biomédica: pros y contras. Bioética \& debat: Tribuna abierta del Institut Borja de Bioètica, n. 50, p. 22-28, 2007. Disponível em: https://www.raco.cat/index.php/BioeticaDebat_es/article/view/259484/346704. Acesso em: 04 out. 2020.

CASABONA, Carlos Maria Romeo. Las prácticas eugenésicas: nuevas perspectivas. In: CASABONA, Carlos Maria Romeo. La eugenesia hoy. Bilbao-Granada:Editorial Comares, 1999.

CHAPMAN, Audrey. Tomorrow's Child: Unlikely to Be Obsolete. The American Journal of Bioethics, v. 19, n. 7, p. 22-23, 2019. Disponível em: https://www.tandfonline.com/doi/full/10.1080/15265161.2019.1618953. Acesso em: 06 out. 2020 .

COBUCCI, Ricardo; DUARTE, Lucélia. Bioética, assistência médica e justiça social. Revista Bioética, v. 21, n. 1, p. 62-66. jan./abr, 2013. Disponível em: https://www.scielo.br/scielo.php?script=sci_arttext\&pid=S1983-80422013000100007. Acesso em: 06 out. 2020.

DEWITT, Mark; MAGIS, Wendy; BRAY, Nicolas; et al. Selection-free genome editing of the sickle mutation in human adult hematopoietic stem/progenitor cells. Science Translational Medicine, $\quad$ v. $\quad 8, \quad$ n. $360, \quad 2016 . \quad$ Disponível em: https://stm.sciencemag.org/content/8/360/360ra134. Acesso em: 06 out. 2020.

DING, Xiong; YIN, Kun; LI, Ziyue; et al. All-in-One Dual CRISPR-Cas12a (AIOD-CRISPR) Assay: A Case for Rapid, Ultrasensitive and Visual Detection of Novel Coronavirus SARSCoV-2 and HIV vírus. bioRxiv, mar 2020. Disponível em: https://www.biorxiv.org/content/10.1101/2020.03.19.998724v1. Acesso em: 06 out. 2020.

FURTADO, Rafael. Edição genética: riscos e benefícios da modificação do DNA humano. Revista Bioética, v. 27, n. 2, p. 223-233, abr/jun 2019. Disponível em: https://www.scielo.br/scielo.php?script=sci_arttext\&pid=S198380422019000200223\&tlng=pt Acesso em: 06 out. 2020. 
GÜELL, Marc. Gene editing in translational research. Revista de Bioética y Derecho, n. 47, p. 5-15, nov. 2019. Disponível em: https://revistes.ub.edu/index.php/RBD/article/view/28570 Acesso em: 06 out. 2020.

HABERMAS, Jürgen. O futuro da natureza humana. A caminho de uma eugenia liberal? Tradução de Karina Janini. São Paulo: Martins Fontes, 2004.

KUHN, Thomas. A estrutura das revoluções científicas. Tradução de Beatriz Vianna Boeira e Nelson Boeira. São Paulo: Perspectiva, 1998.

JIMÉNEZ, Pilar Nicoláz. Carlos María Romeo Casabona. Revista Iberoamericana de Bioética, n. 3, p. 1-13, 2016. Disponível em: https://revistas.comillas.edu/index.php/bioeticarevista-iberoamericana/article/view/7661/7480. Acesso em: 04 out. 2020.

LACADENA, Juan Ramon. Edición genómica: ciencia y ética. Revista Iberoamericana de Bioética, n. 3, p. 1-16, 2017. Disponível em: https://revistas.comillas.edu/index.php/bioeticarevista-iberoamericana/article/view/7665. Acesso em: 04 out. 2020.

LEDFORD, Heidi. Biohackers gear up for genome editing. Nature, v. 524, p. 398-399, 2015. Disponível em: https://www.nature.com/news/biohackers-gear-up-for-genome-editing1.18236. Acesso em: 06 out. 2020.

MAEDER, Morgan; GERSBACH, Charles. Genome-editing technologies for gene and cell therapy. Molecular Theraphy, v. 24, p. 430-446, 2016. Disponível em: https://doi.org/10.1038/mt.2016.10. Acesso em: 06 out. 2020.

MARFANY, Gemma. Interrogantes y retos actuales de la edición genética. Revista de Bioética y Derecho, n. 47, p. 17-31, nov. 2019. Disponível em: https://revistes.ub.edu/index.php/RBD/article/view/28551. Acesso em: 04 out. 2020.

MEIRELLES, Ana Thereza. A proteção à naturalidade do patrimônio genético face à proposta da eugenia liberal: o futuro da natureza humana em Jürgen Habermas. Revista de Biodireito e Direito dos Animais. vol. 3, n. 2, p, 1-17, 2017. Disponível em: https://www.indexlaw.org/index.php/revistarbda/article/view/2301. Acesso: 04 out. 2020.

MEIRELLES, Ana Thereza. Neoeugenia e reprodução humana artificial. Limites éticos e jurídicos. Salvador: Editora JusPodivm, 2014.

NARDI, Nance Beyer; TEIXEIRA, Leonardo Augusto Karam; SILVA, Eduardo Filipe Ávila da. Terapia gênica. Ciência e Saúde Coletiva, 7(1):109-116, 2002. Disponível em: https://www.scielosp.org/pdf/csc/2002.v7n1/109-116/pt. Acesso em: 03 out. 2020.

NATIONAL ACADEMIES OF SCIENCES, ENGINEERING, AND MEDICINE. Committee on Human Gene Editing: Scientific, Medical, and Ethical Considerations. Human Genome Editing: Science, Ethics, and Governance. Washington, DC: National Academies Press, 2017. Disponível em: https://www.ncbi.nlm.nih.gov/books/NBK447270/. Acesso em: 06 out. 2020.

SANDEL, Michael. Contra a perfeição: Ética na era da engenharia genética. Tradução de Ana Carolina Mesquita. 3. ed. Rio de Janeiro: Ed. Civilização Brasileira, 2018. 
SANTALÓ, Josep; CASADO, María. Documento sobre bioética y edición genómica en humanos. Barcelona: Edicions de la Universitat de Barcelona, 2016. Disponível em: http://hdl.handle.net/2445/105022. Acesso em: 06 out. 2020.

WATSON, James; CRICK, Francis. Molecular Structure of Nucleic Acids: A Structure for Deoxyribose Nucleic Acid. Nature, v. 171, p. 737-738, 1953. Disponível em: https://www.nature.com/articles/171737a0. Acesso em: 06 out. 2020.

XU, Lei; WANG, Jun; LIU, Yulin; et al. CRISPR-edited stem cells in a patient with HIV and acute lymphocytic leukemia. New England Journal of Medicine, v. 381, p. 1240-1247, 2019. Disponível em: https://www.nejm.org/doi/full/10.1056/NEJMoa1817426. Acesso em: 06 out. 2020.

Submissão em 9/10/2020 / Aceito em 05/11/2020 